\title{
IgE mediated food allergy in Turkey: different spectrum, similar outcome
}

\author{
Ayşegül Akarsu $^{1 \oplus}$, Melike Ocak ${ }^{1 \oplus}$, Gizem Köken ${ }^{2 \oplus}$, Ümit Murat Şahiner $^{1 \oplus}$, \\ Özge Soyer ${ }^{1 \oplus}$, Bülent Enis Şekerel ${ }^{10}$ \\ ${ }^{1}$ Division of Pediatric Allergy, ${ }^{2}$ Department of Pediatrics, Hacettepe University Faculty of Medicine, Ankara, Turkey.
}

\begin{abstract}
Background. Food allergies (FAs) potentially differ across cultures.

Methods. All medical records of 534 children and adolescents with IgE-mediated FA over a 5-year period were reviewed to document the regional characteristics with regard to spectrum and outcome.

Results. According to their last visit, the most common FAs were tree nuts (TNs) (52.4\%), cow's milk (27.3\%), seeds $(24.7 \%)$, egg white $(23.2 \%)$ and peanuts (14.9\%). Hazelnut and Anacardia nuts were the most common etiologies for TN allergies, whereas lentils and chickpeas for legumes and sesame and pumpkin seed for seeds were most common, respectively. TN allergy was in first place in school-age children (55.3\%) and adolescents $(57.1 \%)$ while in the second place in preschoolers (57.7\%) after egg white (60\%). Of these 534 children, $59.2 \%$ had at least one resolved FA (mainly egg white, cow's milk) and $21 \%$ had no residual FA during the study period. Emerging FAs (fish, shellfish, fruit, TN and seed) after the age of 3 years was reported in 94 children. The prevalence of current asthma $(22.3 \%, 38.2 \%, 40 \%)$ and allergic rhinitis $(11.6 \%, 45.2 \%, 60 \%)$ increased, while current atopic dermatitis $(17.5 \%, 8.6 \%, 8,6 \%)$ decreased in preschoolers, school age children and adolescents, respectively.

Conclusions. The FA spectrum of Turkish children and adolescents differs from many regions of the world with high rates of TN (hazelnut, Anacardia nuts), seed (sesame, pumpkin seed) and lentils, and low rates of soy, peanut and seafood allergies. However, resolution, emergence and persistence of allergies and comorbidities are similar, which points to the limited role of the environment in the outcome.
\end{abstract}

Key words: allergic rhinitis, atopic dermatitis, asthma, food allergy, prevalence.

Although the prevalence of food allergy (FA) peaks in early childhood, there has been a shift in understanding from thinking of FA as a disease that passes over time to understanding that FA can have a heterogeneous natural history. ${ }^{1}$ The natural history can range from early/late recovery to permanent disease, and is accompanied by the emergence of new allergies and atopic comorbidities. The focus on FA in early life is largely due to the early onset of the disorder and the disappearance of many FA in early childhood. ${ }^{2}$ Persistent FA beyond infancy

$凶$ Bülent Enis Şekerel

b_sekerel@yahoo.com

Received 28th October 2020, revised 8th January 2021, accepted 17th February 2021. and toddler is common and clinical appearances may vary between age groups. ${ }^{3}$

The primary objective of this study is to reveal the spectrum of IgE-mediated FA in preschooler, school age children and adolescents in Turkey. Secondary objectives are to examine the relationship between FA and comorbid atopic diseases and the short-term prognosis of FA.

\section{Material and Methods}

\section{Study population}

This study is a retrospective analysis of the characteristics of IgE-mediated FAs in children aged 3-18 years at Hacettepe University Pediatric 
Allergy Department, a tertiary reference center for the entire country of Turkey. The children over 24-months old with IgE-mediated FA who had at least one visit between 1 January 2015 and 1 January 2020 were enrolled in the study. Approval was obtained from non-interventional clinical researches ethics committee

(Hacettepe University Non-interventional Clinical Researches Ethics Board GO20/398, 2020/09-43).

The diagnosis of FA was based on the following two criteria:

1. Positive skin prick test (SPT $\geq 3 \mathrm{~mm}$ than negative control) and/or positive specific IgE (sIgE $\geq 0.35 \mathrm{kU} / \mathrm{L}$ ) PLUS positive oral food challenge (OFC) or a consistent and clear-cut history of food related IgEmediated symptoms within 2 hours after the ingestion of the culprit food in last 12-months.

2. SPT wheal diameters or sIgE levels of the culprit food suggesting clinical reactivity with $>95 \%$ positive predictive value (PPV) in last 12 -months (Table I). ${ }^{1,45}$ If $95 \%$ PPV is not clearly defined, the following criteria were used: $\mathrm{SPT} \geq 8 \mathrm{~mm}$ and/or $\operatorname{sIgE} \geq$ $15 \mathrm{kU} / \mathrm{L} .{ }^{1,4,6}$

In order to evaluate age group characteristics, groups were formed as preschoolers (3-5 years old), school-age children (6-12 years old) and adolescents (13-18 years old). The patients had several outpatient visits during the fiveyear period of the study. While examining the

Table I. $>95 \%$ positive predictive values according to food allergen. ${ }^{1,4,5}$

\begin{tabular}{lcc}
\hline \multirow{2}{*}{ Food } & \multicolumn{2}{c}{ 95\% Positive predictive value } \\
\cline { 2 - 3 } & SPT $(\mathrm{mm})$ & $\mathrm{sIgE}(\mathrm{kU} / \mathrm{L})$ \\
\hline Egg white & $\geq 7$ & $\geq 7$ \\
Cow's milk & $\geq 8$ & $\geq 15$ \\
Tree nut & $\geq 8$ & $\geq 15$ \\
Peanuts & $\geq 8$ & $\geq 15$ \\
Sesame seeds & $\geq 14$ & \\
Fish & $\geq 20$ & \\
\hline
\end{tabular}

characteristics of the age groups to analyze prevalence of asthma, atopic dermatitis (AD), allergic rhinitis (AR), and food allergen groups, one patient was allowed to take part in two groups (Fig. 1). The analyses except the ones which depend on the age group distribution were made according to "current" (the food allergies and atopic diseases at last visit as "current FA", "current asthma" and "current $\mathrm{AD}^{\prime}$ ) or "ever" status (the patients' resolved and/or current IgE-mediated food allergies and atopic diseases as "FA ever", "asthma ever", and "AD ever"). ${ }^{7}$

In the study, tree nuts (TN) were defined as almond, hazelnut, walnut and Anacardia nuts (cashew and pistachio), legumes included lentils, peas, chickpeas and soy, seeds consisted of sesame, poppy seed, sunflower seed and pumpkin seed. Peanuts were individually analyzed, not included to the TN or legumes groups.

\section{Resolved Food Allergies}

The tolerance to the culprit food allergens was collected from the patients' full medical records and histories. The tolerance was determined with negative OFC test result according to PRACTALL. 8

\section{Comorbidities and Aeroallergen sensitization}

The diagnosis of $\mathrm{AD}, \mathrm{AR}$ and asthma/ recurrent wheezing was made according to the international guidelines. ${ }^{9-11}$ The age of asthma diagnosis was determined as the start of asthma

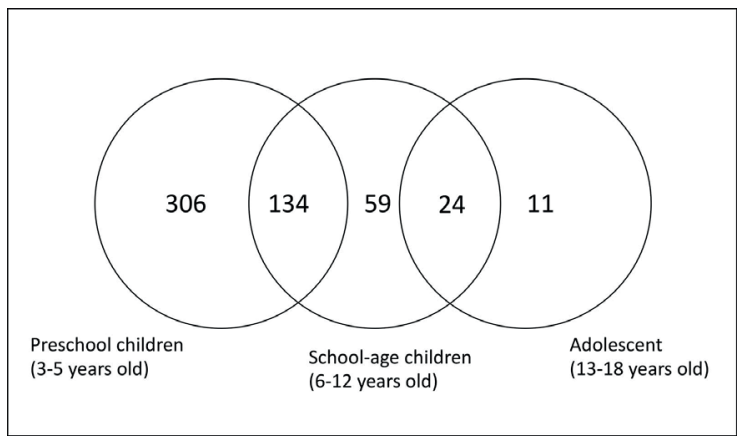

Fig. 1. Shema of the study. 
controller therapy. The age of onset of AR was considered to be the age at which the patient showed signs of rhinitis when exposed to the aero-allergen that she/he was sensitive to.

\section{Skin Prick Test, total and specific IgE measurements}

SPTs were performed with culprit foods and aeroallergens from the patient's clinical history and its cross-reactive allergens as panels of aeroallergens (pollens, molds, house dust, cat and dog dander, cockroach), legumes (lentils, peas, chickpeas, peanuts), tree nuts (almonds, hazelnuts, walnuts, cashews, pistachios, sesame, peanuts) and seeds (sesame, poppy seed, sunflower seed, pumpkin seed). SPTs were applied on the volar face of forearms or upper backs of the patients and wheal size was measured after 15 minutes. ${ }^{12}$ Total IgE and sIgE for food allergens were measured in the sera using Immuno-CAP method (Thermo Fisher Scientific, Uppsala, Sweden).

\section{Statistical Analysis}

SPSS version 22.0 statistical software package (IBM Corp., Armonk, NY, USA) was used for statistical analyses. The data including age, total $\mathrm{IgE}$, absolute eosinophil count variables were not normally distributed; therefore the results were described as medians and interquartile ranges (IQR). The prevalence of all variables, including each allergen, asthma, $\mathrm{AD}, \mathrm{AR}$ according to the age groups, gender, predominant initial symptoms and family history of atopy were performed using frequencies and percentages. $\mathrm{P}$ $<.05$ was considered significant for all analyses.

\section{Results}

A total of 534 patients (M/F: 359/175) enrolled in the study. The median ages at the diagnosis of FA and last visit were 6 months (IQR: 5 7.63 months) and 4.3 years (IQR: 3 - 6.9 years), respectively. The majority of the patients had an 'ever' diagnosis of $\mathrm{AD}(\mathrm{n}=311,58.2 \%)$ and multiple FA ( $\geq 2$ food category) ( $n=364,68.2 \%$ ) (Table II).
Table II. Demographic and clinical features of patients.

\begin{tabular}{lr}
\hline Total number of patients & 534 \\
Gender (male) & $359(67.2)$ \\
Age at diagnosis of FA, & \\
months, median (IQR) & $6(5-7.63)$ \\
$\quad$ Cow's milk & $6(4.5-6)$ \\
Egg white & $6(5-6)$ \\
Tree nuts & $12(9-18)$ \\
Peanuts & $18(11-30)$ \\
Legumes & $9(7-13.25)$ \\
Seeds & $15(9-25)$ \\
Wheat & $6(5-8)$ \\
Fish & $21(13-28)$ \\
Shellfish & $85.5(49--)$ \\
Kiwi & $25(16.5-39.5)$ \\
Banana & $41(7.75-167.25)$
\end{tabular}

Age at last visit, years, median (IQR)

Predominant initial symptoms*

Atopic dermatitis
Urticaria
Angioedema
Anaphylaxis
Nausea, vomiting
Diarrhea
Cough
Other

$216(40.4)$

Number of allergies according food groups

Ever

Total tolerance

Current

1

$230(43.1) \quad 170(31.8)$

2

$101(18.9) \quad 145(27.2)$

3

$50(9.4) \quad 102(19.1)$

$\geq 4$

$41(7.7) \quad 117(21.9)$

$99(18.5) \quad 311(58.2)$

Atopic dermatitis

$154(28.8) \quad 196(36.7)$

Asthma/Recurrent wheezing

$127(23.8) \quad 127(23.8)$

Allergic rhinitis

$271(50.7)$

$184(34.5)$

$181(65.6-640)$

$300(200-600)$

$3.9(2.3-6.8)$

AEC, $\mathrm{mm}^{3}$, median (IQR)

Eosinophils, \%, median (IQR)

Values are $\mathrm{n}(\%)$ unless otherwise indicated

*All patients met the inclusion criteria as mentioned in

Methods section. 


\section{Food Allergies at Last Visit (Current FA)}

The most common FA at the last visit of patients was tree nut allergy $(\mathrm{n}=280,52.4 \%)$ followed by cow's milk ( $n=146,27.3 \%)$, seeds $(n=132$, $24.7 \%)$, egg white $(\mathrm{n}=124,23.2 \%)$ and peanuts $(\mathrm{n}=80,15 \%)$ allergies (Figs 2-4). Many patients with TN allergy suffered from multiple TN $(\geq 2$ $\mathrm{TN})$ allergies ( $\mathrm{n}=202,72.1 \%)$. Among tree nuts, legumes and seed groups, the most common food allergens were hazelnuts, lentils and sesame, respectively (Fig. 3A, 3B, 3C). None of the patients had soy allergy.

\section{Food Allergies and Comorbid Atopic Diseases According to Age Groups}

Preschool children (3 - 5 years old)

Most of the patients had egg white allergy $(\mathrm{n}=264,60 \%)$ followed by TN ( $\mathrm{n}=254,57.7 \%)$ and cow's milk ( $\mathrm{n}=216,49.1 \%$ ) (Fig. 2A, 2B). The detection of FA in $>90 \%$ of preschool children with any kind of FA necessitated testing with 3 foods: egg white $(60 \%)$ plus hazelnuts (sum $=$ $83.5 \%$ ) plus cow's milk (sum $=96.4 \%$ ).
Twenty- five percent of the patients $(n=113)$ had recurrent wheezing or diagnosis of asthma. Ninety-eight out of 113 (86.7\%) patients were receiving asthma controller-therapy at their last visits. Fifty-one children (11.6\%) had AR and the most common aeroallergen was pollen $(n=26,51 \%)$ followed by dust mite $(n=25,49 \%)$ (Fig. 3D). Though $63.6 \%(n=280)$ of the patients had an 'ever' AD history, $17.5 \%(\mathrm{n}=77)$ of the patients had 'current' AD at last visit (Fig. 2C).

School-age children (6-12 years old)

Tree nut allergy ( $n=120,55.3 \%)$ was the most frequent FA followed by cow's milk ( $n=65,30 \%)$ and egg white ( $\mathrm{n}=60,27.6 \%)$ allergies (Fig. 2A, 2B). Among the individual food groups, the most frequent allergens were hazelnuts $(n=99$, $45.6 \%$ ), Anacardia nuts (pistachios [ $\mathrm{n}=76,35 \%]$ and cashews $[\mathrm{n}=69,31.8 \%])$ and walnuts $(\mathrm{n}=69$, $31.8 \%$ ). The detection of FA in $>90 \%$ of school children with any kind of FA necessitated testing with the same 3 foods with preschool children: hazelnuts $(55.3 \%)$ plus cow's milk (sum=79.3\%) plus egg white (sum=91\%).
A

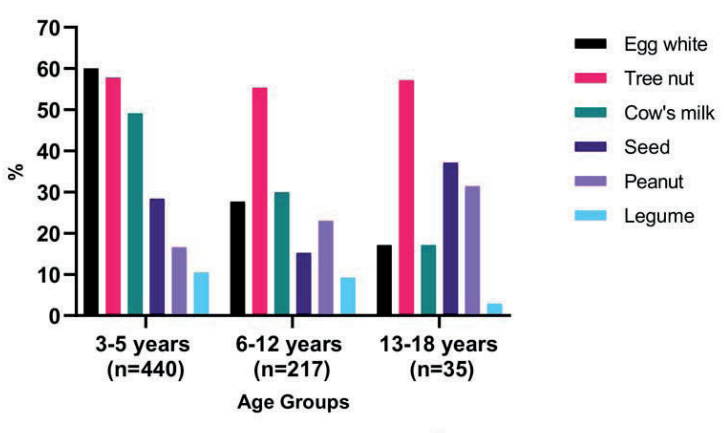

B

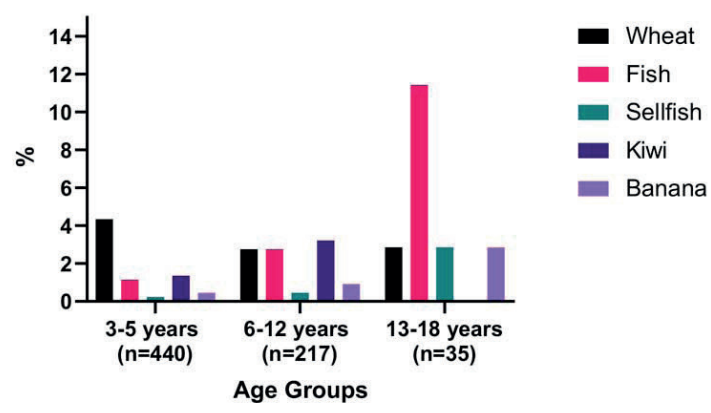

C

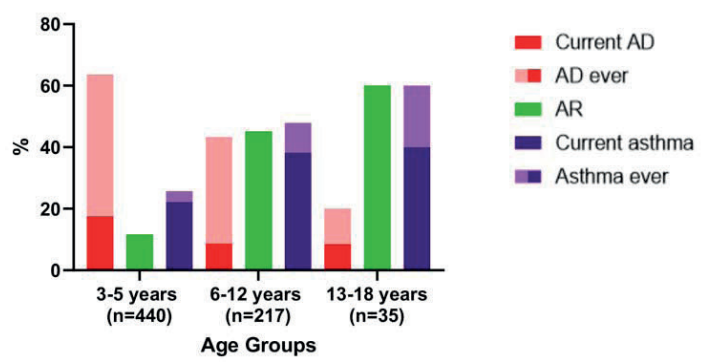

Fig. 2. Distribution of (A) most common and (B) less common food allergies, (C) current and ever atopic diseases according to age groups. AD: atopic dermatitis, AR: allergic rhinitis. 
A

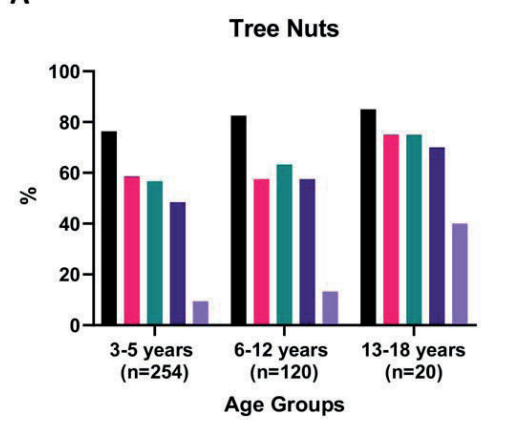

C

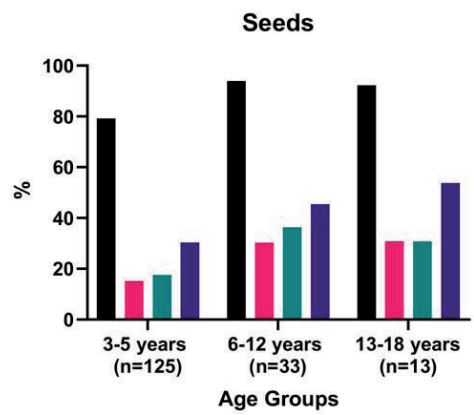

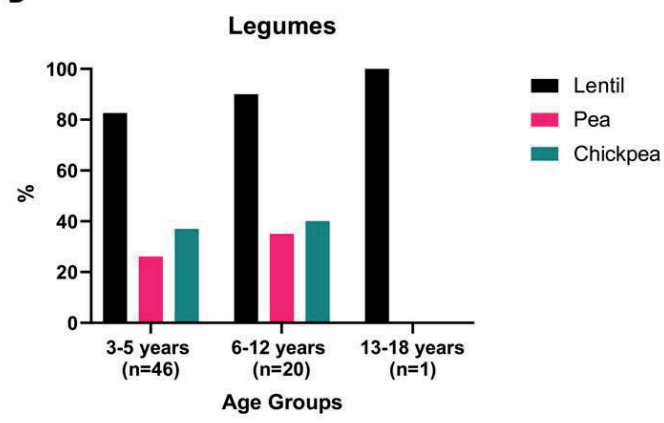

D

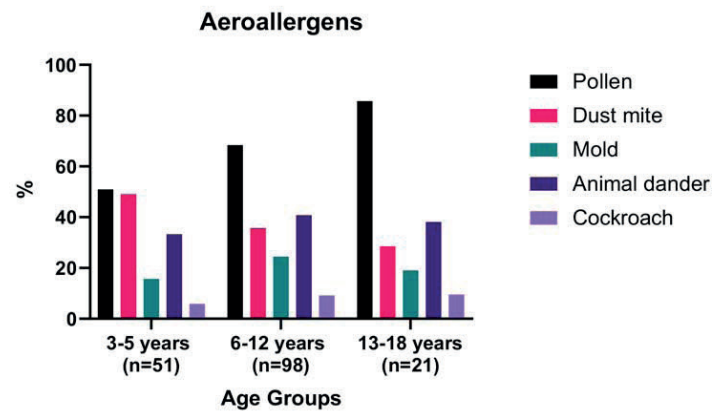

Fig. 3. Distribution of allergens by age (A) in tree nuts (B) in legumes (C) in seeds and (D) in aeroallergen sensitization.

Approximately half of the patients had asthma diagnosis ( $\mathrm{n}=104,47.9 \%)$ and AR ( $\mathrm{n}=98,45.2 \%)$ while $79.8 \%$ of the asthmatic patients $(n=83)$ were using asthma controller therapy at their last visits. The most prevalent aeroallergens were pollens $(\mathrm{n}=67,68.4 \%)$ and animal dander $(n=40,40.8 \%)$ (Fig. 3D). Though $43.3 \%(n=94)$ of the patients had 'ever' AD, 8.6\% ( $\mathrm{n}=19)$ of the school children had 'current' AD (Fig. 2C).

\section{Adolescents (13-18 years old)}

Tree nuts $(\mathrm{n}=20,57.1 \%)$ were the most common food allergen followed by seeds $(n=13,37.1 \%)$ and peanuts ( $\mathrm{n}=11,31.4 \%$ ) allergies (Fig. 2A, 2B). Individually, hazelnuts ( $\mathrm{n}=17,48.6 \%)$, Anacardia nuts (cashews [n=15, 42.9\%], and pistachios $[n=15,42.9 \%])$ allergies were the most frequent FAs. The detection of FA in $>90 \%$ of adolescents with any kind of FA necessitated testing with 5 foods: hazelnuts $(48.6 \%$ ), plus cow's milk (sum= $71.4 \%$ ) plus sesame (sum $=82.8 \%$ ) plus egg white $(\mathrm{sum}=88.6 \%)$ and walnuts (sum $=91.4 \%)$.

The majority of the adolescents had asthma $(n=21,60 \%)$ and AR $(n=21,60 \%)$. Most of the adolescents with asthma ( $\mathrm{n}=14,66.6 \%)$ were using any asthma-controller therapy at their last visits. Only $8.6 \%$ of the adolescents $(n=3)$ had $\mathrm{AD}$ at their last visits, while $20 \%(\mathrm{n}=7)$ of adolescents had 'ever' AD diagnosis (Fig. 2C).

Comparisons of food allergies and comorbidities by age groups

Egg white allergy frequency significantly decreased $(p=0.002)$ in contrast to peanut allergy which increased $(p=0.001)$ with respect to age. Current asthma and AR prevalence were higher in older children while current AD prevalence was decreasing with respect to age (Fig. 2C).

\section{Resolved food allergies}

The median follow-up period of the patients was 30.9 months (IQR:16.6-48.3 months) in the 5 year- study period. At their last visits, 316 patients $(59.2 \%)$ had tolerance to at least one group of the allergens. In addition, 112 patients (21\%) had tolerance to all of the foods which they previously had allergies (Table II). 
According to the histories and medical records of the patients egg white $(64.7 \%)$, wheat $(52.6 \%)$, cow's milk (51.3\%), lentils (34.6\%) and fish $(27.7 \%)$ allergies had higher resolution rate than those of other food allergies. Almonds (22.2\%) and cashews $(7.8 \%)$ had the highest and the lowest tolerance rate among TNs, respectively. In the seed group, they were sesame (21\%) and sunflower seeds $(3.3 \%)$, respectively. None of the patients with shellfish and kiwi allergy had tolerance to culprit foods at the last visit (Fig. 4).

\section{Emerging food allergies}

Although allergies with cow's milk, egg white and wheat have been diagnosed before the age of 3 years, some patients with seeds $(n=40$, $25.5 \%), \operatorname{TN}(n=37,12 \%)$, legumes $(n=5,10 \%)$, kiwi $(n=5,50 \%)$, banana $(n=2,50 \%)$, fish $(n=3$, $27.3 \%)$ and shellfish $(\mathrm{n}=2,100 \%)$ allergies were diagnosed after the age of 3 .

\section{Discussion}

In this study, we showed that the spectrum of food allergies differs based on age group. Egg white was the most common allergen in preschool children and the rate decreased with age whereas the majority of school age children and adolescents had TN allergy. The comparison of comorbidities based on age groups showed that the prevalence of current asthma and AR increased with age in contrast to AD.

The prevalence of individual food allergies differed significantly based on the geographic regions, the associated dietary habits and the methods of the studies. In the US, a survey analysis showed that the most frequent FA was peanuts in all age groups followed by cow's milk and TN in preschool children, shellfish and cow's milk in school-age children and adolescents. ${ }^{3}$ A randomized telephone survey from 10 European nations indicated cow's milk allergy $(38.5 \%)$ was the most frequent reported FA, followed by fruits (29.5\%) and eggs (19\%). ${ }^{13}$ The meta-analysis done by EAACI Food allergy and Anaphylaxis Guidelines Group revealed that cow's milk, TN and soy allergies were the most frequent food-challenge-defined FAs in Europe. ${ }^{14}$ In the SchoolNuts study, peanut, $\mathrm{TN}$ and egg were the most frequent FAs in Australian early adolescents. ${ }^{15}$ Another study in Hong Kong Chinese preschoolers reported that the most frequent adverse food reactions were caused by shellfish, egg and peanuts. ${ }^{16}$ In contrast to those studies, we found that most of the 3-18 years old children had TN allergy (52.4\%) at last visits followed by cow's milk $(27.3 \%)$ and seeds $(24.7 \%)$ allergies. In addition, the frequency of peanut allergy was not as high as reported in the studies of other countries and only 2 patients $(0.4 \%)$ had shellfish allergy while none of the patients had soy allergy. The differences in the distribution and prevalence
A

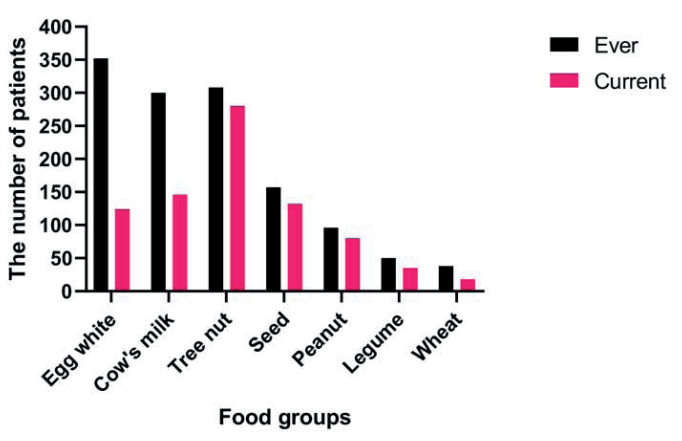

Fig. 4. Distribution of current and ever food allergies.

B

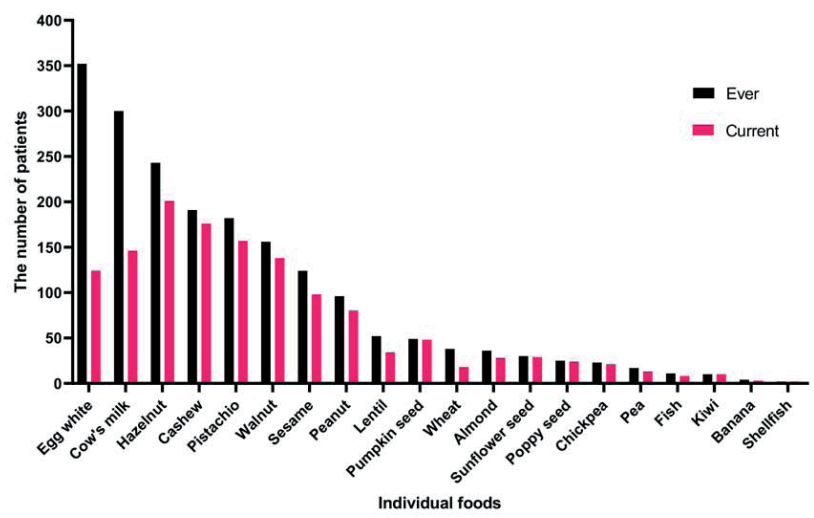


of FAs may arise from the culinary variations of countries and methods of the studies as selfreported or physician diagnosed. Turkey holds an important place in the production of TN in worldwide. ${ }^{17}$ The higher rate of TN allergy in Turkey could be the result of high consumption of TN. On the other hand, peanut consumption in Turkey was not as high as in other countries that could explain the lower rate of peanut allergy in our study compared to the rates reported in the literature. ${ }^{17}$ The recent studies reported that the prevalence of sesame allergy has been increasing in last years. ${ }^{18-20}$ Similar to those studies, we found that sesame was one of the most important FA in adolescents. The explanation for the increase of sesame allergy may be an increased awareness of these "rare" FAs, as well as changing dietary habits. Similar to EAACI report, we found that egg white allergy was more prevalent among younger children $(\mathrm{p}=0.002)$, while the frequency of peanut allergy was higher among older children $(p=0.001) \cdot{ }^{14}$ In addition, TN allergy was more common among school-age and adolescent groups. Although, seafood allergies were common in Middle East and Mediterranean areas, only 13 patients $(2.4 \%)$ had seafood allergy in our cohort. ${ }^{21,22}$

In the previous report from Turkey which enrolled the children aged 0.1-19 years, egg white, cow's milk and hazelnuts were the most frequent FAs. ${ }^{23}$ Orhan et al. ${ }^{24}$, reported that beef, cow's milk and cocoa were the most frequent FA in 6-9-year-old urban schoolchildren in the eastern Black Sea region of Turkey. Moreover, the recent study from Turkey has revealed that 0-2 years age children had egg white, cow's milk and TN allergies more frequently compared to other food allergens. ${ }^{20}$ In our cohort, egg white allergy was more common among preschool children similar to the results of previous studies, while TN allergy was the most common FA among school-age children and adolescents and none of the patients had beef or cocoa allergy. The differences in the distribution of FA from previous studies may arise from the resolution of egg white and cow's milk allergies among younger age. ${ }^{25,26}$ Similar to our report, a food-challenged based study form Turkey showed that TN and peanuts were the most frequent FAs among adolescents. ${ }^{27}$ In addition, we found that seed allergy, especially sesame $(34.2 \%)$, had similar prevalence with peanut $(31.4 \%)$ in adolescents.

Tree nut allergy spectrum also varied among studies. In the HealthNuts and SchoolNuts studies, cashews were defined as the most frequent TN allergy in the first 6 years of life and early adolescence followed by hazelnuts and pistachios, respectively. ${ }^{15,28}$ In USA, walnuts and cashews were reported as the most common TN allergies, recently another parent-reported study showed that almonds and cashews were more common. While hazelnuts were the most frequent TN allergy in Europe, Brazil nuts, almonds and walnuts were the most common ones in the UK. ${ }^{29}$ In our study, hazelnuts were the most frequent TN allergy followed by Anacardia nuts in all age-groups in the line of previous studies from Turkey. ${ }^{30,31}$ Turkey supplies approximately $75 \%$ of worldwide hazelnut production and it is estimated that Turkish people rank third among nations in the consumption of hazelnuts. ${ }^{17}$ Similarly, Turkey had an important role in the production of pistachios (in third place) and was reported as the country having the highest rate of pistachio consumption. ${ }^{17}$ The possible reason for the high rate of hazelnut and pistachio in our study can be explained by the high consumption of these nuts. Although cashews are not frequently consumed in Turkey, because of significant cosensitization and co-allergy with pistachios, we found that the rate of cashew allergy was as high as pistachio. ${ }^{32}$

In previous studies, the co-occurrence of other atopic diseases with FA has been well defined. ${ }^{33}$ Adding to this, we reported the similar prevalence of $\mathrm{AD}$, asthma and $\mathrm{AR}$ in children with FA. In addition, the incidence of asthma and $A R$ was increased age although lower age for $\mathrm{AD}$, in the line of previous knowledge. ${ }^{34,35}$ These findings revealed that the frequency and natural history of comorbid allergic diseases was similar to Western countries in spite of the different spectrum of FAs. 
This short-term longitudinal study documents the spectrum of food allergies while providing data on their prognosis as a secondary outcome. As the diagnosis of food allergy is not entirely based on OFC, the results differ in both OFCbased and single food-focused studies, however they are valuable to reflect daily practice. Although, it can be assumed that some allergies are only sensitization, the fact that cow's milk and hen's egg allergies have a higher tolerance rate and early age for the diagnosis compared to other allergies is compatible with the literature. ${ }^{2}$ Similar to previous reports, we found that egg white $(64.7 \%)$, wheat (52.6\%), cow's milk (51.3\%) allergies had higher resolution ratio than that of TN allergy (7.8\% to $22.2 \%)$. We also found that the resolution rate of seed allergy (3.3\% to $21 \%)$ was similar to that of TN allergy which was consistent with the previous study that reported $80 \%$ persistence of sesame allergy. ${ }^{36}$

In our study, the diagnosis of cow's milk, egg white and wheat allergy was made in the first 2 years of life in all patients, while some seeds, $\mathrm{TN}$, legumes, fruit and seafood allergies were diagnosed after the age of 3. An older age during diagnosis can be explained either by the fact that delayed development of these allergies occurs or these patients have not encountered these foods before that age. Although the exact explanation goes beyond the scope of this study, the late onset age of these foods is compatible with the literature. ${ }^{29}$

The limitation of this study is that the diagnosis of FA was not totally based on OFC results. Therefore, the patients who had SPT or IgE values with the culprit food suggesting clinical reactivity with $>95 \%$ PPV were enrolled in the study to minimize the inaccuracy of the diagnosis of FA. The other limitation is that the number of patients in the adolescent group is too low to make strong conclusions. The strength of our study is that it is the first study which focuses on the FA spectrum, comorbid atopic diseases and natural prognosis in children aged 3-18 years from the Eastern Mediterranean region. The other strengths of our study are the inclusion of a large patient group, the documentation of allergy frequencies within food groups and real-life data.

In conclusion, FA spectrum of Turkish children is different from many cultures, but the outcome of allergies and comorbidities are similar pointing out to the role of the environment in the development but not in the natural history.

\section{Author contribution}

The authors confirm contribution to the paper as follows: study conception and design: BEŞ; data collection: AA, MÖ, GK; analysis and interpretation of results: AA, ÜMŞ, ÖS, BEŞ; draft manuscript preparation: AA, BEŞ. All authors reviewed the results and approved the final version of the manuscript.

\section{Ethical approval}

Approval was obtained from non-interventional clinical researches ethics committee

(Hacettepe University Non-interventional Clinical Researches Ethics Board GO20/398, 2020/09-43).

\section{Source of funding}

No funding was received for this study.

\section{Conflict of interest}

The authors declare that they have no conflict of interest.

\section{REFERENCES}

1. Sampson HA, Aceves S, Bock SA, et al. Food allergy: a practice parameter update-2014. J Allergy Clin Immunol 2014; 134: 1016-1025.e43.

2. Savage J, Johns CB. Food allergy: epidemiology and natural history. Immunol Allergy Clin North Am 2015; 35: 45-59.

3. Gupta RS, Springston EE, Warrier MR, et al. The prevalence, severity, and distribution of childhood food allergy in the United States. Pediatrics 2011; 128: e9-e17. 
4. Stiefel G, Anagnostou K, Boyle RJ, et al. BSACI guideline for the diagnosis and management of peanut and tree nut allergy. Clin Exp Allergy 2017; 47: 719-739.

5. Saf S, Sifers TM, Baker MG, et al. Diagnosis of sesame allergy: analysis of current practice and exploration of sesame component ses i 1. J Allergy Clin Immunol Pract 2020; 8: 1681-1688.e3.

6. Clark AT, Ewan PW. Interpretation of tests for nut allergy in one thousand patients, in relation to allergy or tolerance. Clin Exp Allergy 2003; 33: 10411045.

7. Peters RL, Koplin JJ, Gurrin LC, et al; HealthNuts Study. The prevalence of food allergy and other allergic diseases in early childhood in a populationbased study: HealthNuts age 4-year follow-up. J Allergy Clin Immunol 2017; 140: 145-153.e8.

8. Sampson HA, Gerth van Wijk R, Bindslev-Jensen C, et al. Standardizing double-blind, placebo-controlled oral food challenges: American Academy of Allergy, Asthma \& Immunology-European Academy of Allergy and Clinical Immunology PRACTALL consensus report. J Allergy Clin Immunol 2012; 130: 1260-1274.

9. Eichenfield LF, Tom WL, Chamlin SL, et al. Guidelines of care for the management of atopic dermatitis: section 1. diagnosis and assessment of atopic dermatitis. J Am Acad Dermatol 2014; 70: 338351.

10. Bousquet J, Schunemann HJ, Togias A, et al; Allergic Rhinitis and Its Impact on Asthma Working Group Next-generation Allergic Rhinitis and Its Impact on Asthma (ARIA) guidelines for allergic rhinitis based on Grading of Recommendations Assessment, Development and Evaluation (GRADE) and realworld evidence. J Allergy Clin Immunol 2020; 145: 70-80.e3.

11. Global Strategy for Asthma Management and Prevention. https://ginasthma.org/wp-content/ uploads/2020/04/GINA-2020-full-report_-final-_ wms.pdf (Accessed on July 18, 2021).

12. Kahveci M, Karabulut E, Soyer O, Sahiner UM, Buyuktiryaki B, Sekerel BE. Fine-tuning the use of a skin prick test device. World Allergy Organ J 2020; 13: 100122.

13. Steinke M, Fiocchi A, Kirchlechner V, et al; REDALL Study ConsortiumPerceived food allergy in children in 10 European nations. A randomised telephone survey. Int Arch Allergy Immunol 2007; 143: 290295.
14. Nwaru BI, Hickstein L, Panesar SS, Roberts G, Muraro A, Sheikh A; EAACI Food Allergy and Anaphylaxis Guidelines Group. Prevalence of common food allergies in Europe: a systematic review and metaanalysis. Allergy 2014; 69: 992-1007.

15. Sasaki M, Koplin JJ, Dharmage SC, et al. Prevalence of clinic-defined food allergy in early adolescence: The SchoolNuts study. J Allergy Clin Immunol 2018; 141: 391-398. e4.

16. Leung TF, Yung E, Wong YS, Lam CW, Wong GW. Parent-reported adverse food reactions in Hong Kong Chinese pre-schoolers: epidemiology, clinical spectrum and risk factors. Pediatr Allergy Immunol 2009; 20: 339-346.

17. Nuts \& Dried Fruits Statistical Yearbook 2019/2020 Available at: https://www.nutfruit. org/files/tech/1587539172_INC_Statistical_ Yearbook_2019-2020.pdf (Accessed on September 2, 2020).

18. Warren CM, Chadha AS, Sicherer SH, Jiang J, Gupta RS. Prevalence and severity of sesame allergy in the United States. JAMA Netw Open 2019; 2: e199144.

19. Garkaby J, Epov L, Musallam N, et al. The sesame - peanut conundrum in Israel: reevaluation of food allergy prevalence in young children. J Allergy Clin Immunol Pract 2021; 9: 200-205.

20. Kahveci M, Koken G, Sahiner UM, Soyer O, Sekerel BE. Immunoglobulin E-mediated food allergies differ in East Mediterranean children aged 0-2 years. Int Arch Allergy Immunol 2020; 181: 365-374.

21. Shoormasti RS, Sabetkish N, Kazemnejad A, Vahabi N, Fazlollahi MR, Pourpak Z. Are the most common food allergens in an Iranian atopic population compatible with worldwide reports? A systemic review and meta-analysis with molecular classification of frequent allergens. Allergol Immunopathol (Madr) 2019; 47: 604-618.

22. Lyons SA, Clausen M, Knulst AC, et al. Prevalence of food sensitization and food allergy in children across Europe. J Allergy Clin Immunol Pract 2020; 8: 2736-2746.e9.

23. Yavuz ST, Sahiner UM, Buyuktiryaki B, et al. Phenotypes of IgE-mediated food allergy in Turkish children. Allergy Asthma Proc 2011; 32: 47-55.

24. Orhan F, Karakas T, Cakir M, Aksoy A, Baki A, Gedik Y. Prevalence of immunoglobulin E-mediated food allergy in 6-9-year-old urban schoolchildren in the eastern Black Sea region of Turkey. Clin Exp Allergy 2009; 39: 1027-1035. 
25. Savage JH, Matsui EC, Skripak JM, Wood RA. The natural history of egg allergy. J Allergy Clin Immunol 2007; 120: 1413-1417.

26. Skripak JM, Matsui EC, Mudd K, Wood RA. The natural history of IgE-mediated cow's milk allergy. J Allergy Clin Immunol 2007; 120: 1172-1177.

27. Mustafayev R, Civelek E, Orhan F, Yuksel H, Boz AB, Sekerel BE. Similar prevalence, different spectrum: IgE-mediated food allergy among Turkish adolescents. Allergol Immunopathol (Madr) 2013; 41: 387-396.

28. McWilliam V, Peters R, Tang MLK, et al; HealthNuts Investigators. Patterns of tree nut sensitization and allergy in the first 6 years of life in a populationbased cohort. J Allergy Clin Immunol 2019; 143: 644650.e5.

29. McWilliam VL, Perrett KP, Dang T, Peters RL. Prevalence and natural history of tree nut allergy. Ann Allergy Asthma Immunol 2020; 124: 466-472.

30. Cetinkaya PG, Buyuktiryaki B, Soyer O, Sahiner UM, Sackesen C, Sekerel BE. Phenotypical characterization of tree nuts and peanut allergies in east Mediterranean children. Allergol Immunopathol (Madr) 2020; 48: 316-322.
31. Kahveci M, Akarsu A, Koken G, Sahiner UM, Soyer $\mathrm{O}$, Sekerel BE. Food-induced anaphylaxis in infants, as compared to toddlers and preschool children in Turkey. Pediatr Allergy Immunol 2020; 31: 954-961.

32. Cetinkaya PG, Karaguzel D, Esenboga S, et al. Pistachio and cashew nut allergy in childhood: predictive factors towards development of a decision tree. Asian Pac J Allergy Immunol 2021; 39: 53-61.

33. Boyce JA, Assa'ad A, Burks AW, et al; NIAIDSponsored Expert Panel. Guidelines for the diagnosis and management of food allergy in the United States: summary of the NIAID-sponsored expert panel report. J Allergy Clin Immunol 2010; 126: 1105-1118.

34. Langan SM, Irvine AD, Weidinger S. Atopic dermatitis. Lancet 2020; 396: 345-360.

35. Holgate ST, Wenzel S, Postma DS, Weiss ST, Renz H, Sly PD. Asthma. Nat Rev Dis Primers 2015; 1: 15025.

36. Cohen A, Goldberg M, Levy B, Leshno M, Katz Y. Sesame food allergy and sensitization in children: the natural history and long-term follow-up. Pediatr Allergy Immunol 2007; 18: 217-223. 